\title{
Calibrated cryo-cell UV-LA-ICPMS elemental concentrations from the NGRIP ice core reveal abrupt, sub-annual variability in dust across the GI-21.2 interstadial period
}

\author{
Damiano Della Lunga ${ }^{1,2}$, Wolfgang Müller ${ }^{1}$, Sune Olander Rasmussen ${ }^{3}$, Anders Svensson $^{3}$, and Paul Vallelonga ${ }^{3}$ \\ ${ }^{1}$ Royal Holloway University of London, Egham TW20 0EX, UK \\ ${ }^{2}$ Alfred Wegener Instiutute for Polar and Marine Research, 27570 Bremerhaven, Germany \\ ${ }^{3}$ Centre for Ice and Climate, Niels Bohr Institute, University of Copenhagen, 2100 Copenhagen $\varnothing$, Denmark
}

Correspondence to: Damiano Della Lunga (dellalungadamiano@gmail.com)

Received: 21 October 2016 - Discussion started: 23 November 2016

Revised: 20 April 2017 - Accepted: 21 April 2017 - Published: 31 May 2017

\begin{abstract}
Several abrupt shifts from periods of extreme cold (Greenland stadials, GS) to relatively warmer conditions (Greenland interstadials, GI) called DansgaardOeschger events are recorded in the Greenland ice cores. Using cryo-cell UV-laser-ablation inductively coupled-plasma mass spectrometry (UV-LA-ICPMS), we analysed a $2.85 \mathrm{~m}$ NGRIP ice core section (2691.50-2688.65 m depth, age interval $84.86-85.09 \mathrm{ka} \mathrm{b} 2 \mathrm{k}$, thus covering $\sim 230$ years) across the transitions of GI-21.2, a short-lived interstadial prior to interstadial GI-21.1. GI-21.2 is a $\sim 100$-year long period with $\delta^{18} \mathrm{O}$ values $3-4 \%$ higher than the following $\sim 200$ years of stadial conditions (GS-21.2), which precede the major GI-21.1 warming. We report concentrations of "major" elements indicative of dust and/or sea salt (Na, Fe, $\mathrm{Al}, \mathrm{Ca}, \mathrm{Mg}$ ) at a spatial resolution of $\sim 200 \mu \mathrm{m}$, while maintaining detection limits in the low-ppb range, thereby achieving sub-annual time resolution even in deep NGRIP ice. We present an improved external calibration and quantification procedure using a set of five ice standards made from aqueous (international) standard solutions. Our results show that element concentrations decrease drastically (more than 10fold) at the warming onset of GI-21.2 at the scale of a single year, followed by relatively low concentrations characterizing the interstadial part before gradually reaching again typical stadial values.
\end{abstract}

\section{Introduction}

Dansgaard-Oeschger (D-O) events are abrupt climatic fluctuations between periods of full glacial conditions (called Greenland stadials, GS) and periods of relatively mild conditions during the last glacial (Greenland interstadials, GI) (Rasmussen et al., 2014).

During stadials, deposition of dust and sea salt in Greenland ice significantly increases. Sea-salt aerosols in ice cores are present with several species (e.g. $\mathrm{Na}^{+}, \mathrm{Cl}-$, and $\mathrm{Mg}^{2+}$ ) as major impurities. The source of these particles is bubble bursting over open ocean water (Lewis and Schwartz, 2004), where winds lash vigorously the sea surface. The aerosols are then transported and deposited on the ice cap. This phenomenon is strongest during stadials but also varies within a year, with the aerosol deposition peaking in wintertime (Wolff et al., 2003). This is because storminess over the ocean enhances the transport of sea-salt species inland during cold conditions, although this effect has to counter the typical increase in sea-ice extent during winter that makes it more difficult for sea-salt aerosols to reach a particular site, since they have to travel further (Petit et al., 1999). This mechanism, which is thought to be the primary reason for sea-salt enrichment in ice cores during cooling events, receives possibly further contributions of sea salt from another source. When sea ice is formed, highly saline brine and fragile frost flowers form on top of the frozen surface. This brine represents a potential source of aerosol, carried over land by the wind (Wolff et al, 2003). However, from a quantitative point of view, the contribution of brine, frost flowers, and blow- 
ing snow to the wintertime peak in sea-salt aerosol is still a matter of debate (Huang and Jaeglé, 2017).

Studies suggest that during stadials, the increased storminess and surface wind speed together with the reduced moisture content in the atmosphere and soil facilitate the sharp increases in continental dust transport to polar areas (Yung et al., 1996; Kreutz and Koffman, 2013). The source of Greenland dust includes high-elevation sites and highlatitude steppe in Asia whose area increased during cold, more arid periods (Mahowald et al., 1999).

The determination of the phasing of the different records has always been a key aim of high-resolution investigations of Greenland ice cores in order to determine the exact time sequence of variations in temperature, moisture sources, precipitation, and input of Asian dust and sea salt (e.g. Steffensen et al., 2008). In fact, the phasing of dust records in polar ice cores as inferred from the non-sea-salt fraction of ions (e.g. $\mathrm{Ca}^{2+}, \mathrm{Mg}^{2+}, \mathrm{Al}^{3+}, \mathrm{K}^{+}, \mathrm{Fe}^{2+}$ ), which are largely the result of carbonate and silicate mineral weathering (Lewis and Schwartz, 2004), can be used to reconstruct changes in past climatic conditions and atmospheric circulation (Zhang et al., 1997).

Impurities in ice are measured routinely by continuous flow analysis (CFA), which melts a section of the ice core continuously while measuring different chemical components, such as $\mathrm{Na}^{+}, \mathrm{NH}_{4}^{+}$, dust, and conductivity, in the melt water through several detectors. Depending on melt speed and the characteristics of the analytical set-up, layers with thicknesses down to $\sim 10 \mathrm{~mm}$ can typically be resolved (Bigler et al., 2011; Vallelonga et al., 2012).

The aim of the present study is to assess the sensitivity and the phasing of dust/sea-salt proxies as $\mathrm{Na}^{+}, \mathrm{Fe}^{2+}$, $\mathrm{Al}^{3+}, \mathrm{Ca}^{2+}$ and $\mathrm{Mg}^{2+}$ at a resolution of $\sim 200 \mu \mathrm{m}$ (providing approximately 50 data points per calendar year at this depth) across the abrupt warming into and cooling out of the precursor event GI-21.2 (Capron et al., 2010). Furthermore, we present an updated fully quantitative calibration for the elements under investigation, following Della Lunga et al. (2014) and Müller et al. (2011).

\section{Methods and calibration}

NGRIP ice core samples were initially prepared at the Centre for Ice and Climate, Niels Bohr Institute, Copenhagen. They were cut using a band saw to fit the laser-ablation cryocell sample holder at Royal Holloway University of London (RHUL), which is able to simultaneously hold three ice strips of dimensions $50 \times 11 \times 11 \mathrm{~mm}$ (see Della Lunga et al., 2014). For this study a section of $2.85 \mathrm{~m}$ of NGRIP ice from the depth interval 2688.65-2691.50 m was selected (Fig. 1). This section corresponds to more than 200 years, given the layer thickness of $\sim 10 \mathrm{~mm}$ (Vallelonga et al., 2012). The section covers an age range of $85.09-84.86 \mathrm{ka} \mathrm{b} 2 \mathrm{k}$ and therefore includes GI-21.2 (Rasmussen et al., 2014). We utilized sam-

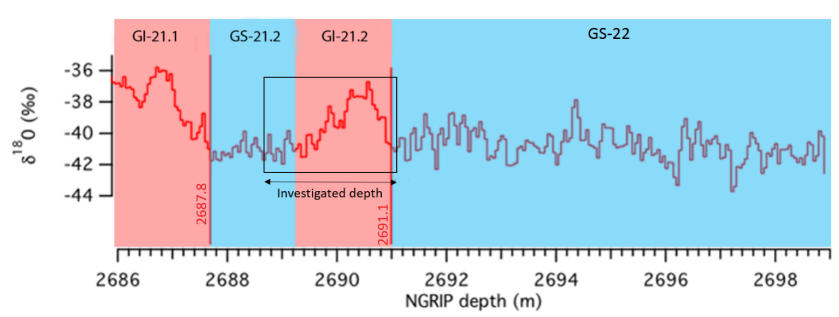

Figure 1. $\delta^{18} \mathrm{O}$ profile across the transition from GS-22 to GI-21.1 (modified from Vallelonga et al., 2012). Stadial and interstadial periods are highlighted in blue and red respectively. The black box and arrow indicate the corresponding section of the ice core analysed for this study.

ples from a similar position within the ice core cross section to Della Lunga et al. (2014).

The analytical methodology of cryo-cell UV-LA-ICPMS used for these analyses follows Müller et al. $(2009,2011)$ and especially Della Lunga et al. (2014), and only a brief summary will be given here. Cleaning of the ice surface has been conducted using a ceramic "major-elements free" Y-doped $\mathrm{ZrO}_{2}$ blade (American Cutting Edge, USA), mounted on a custom-built, acid-cleaned PTFE vice that allows ice scraping in steps of less than $0.5 \mathrm{~mm}$ and surface smoothing in order to remove contamination from handling and cutting. Approximately $2 \mathrm{~mm}$ of ice were removed from all the surfaces about to be analysed. Handling and smoothing procedures were conducted in a clean hood (US 10-100, ISO4-5) utilizing laboratory gloves.

The adopted methodology includes the acquisition of the following mass / charge ratios: 23(Na), 24(Mg), 27( $\mathrm{Al})$, 34(S), 39(K), 40(Ca), 44(Ca), 55(Mn), 56(Fe), 65(Cu), 85(Rb), 88(Sr), 89(Y), 138(Ba), 139(La), 140(Ce), 141(Pr), 147(Sm), 153(Eu), 157(Gd), 172(Yb), and 208(Pb), with dwell times ranging from 5 to $40 \mathrm{~ms}$ (see Della Lunga et al., 2014), and a total sweep time of $550 \mathrm{~ms}$. Among these, only the following usually show a resolvable signal / background ratio and will be displayed as results: 24(Mg), 27(Al), $40(\mathrm{Ca})$, and $56(\mathrm{Fe})$. All elements were acquired in reaction mode, utilizing $4.5 \mathrm{~mL} \mathrm{~min}^{-1}$ of $\mathrm{H}_{2}$ in the octopole cell, allowing the removal of conventional plasma interferences via charge transfer reaction, particularly significant on mass $40(\mathrm{Ca})$ and $56(\mathrm{Fe})$ from ${ }^{40} \mathrm{Ar}$ and ${ }^{40} \mathrm{Ar}^{16} \mathrm{O}$. Formation of hydrides has been monitored on specific isobaric-free masses $(210,233)$ in no-gas and $\mathrm{H}_{2}$ mode and resulted in no significant formation of such compounds in both cases. However, mass 39(K), despite a resolvable signal / background ratio, shows a potential interference from ${ }^{38} \mathrm{ArH}$ resulting from adding $\mathrm{H}_{2}$ in the reaction cell, and therefore will not be considered further. Rare Earth elements were monitored as an indicator of further possible contamination due to smoothing and were not the main target of this study. 
Intensities of isotopes acquired have been recalculated as elemental intensities based on their relative isotopic abundance (Berglund and Wieser, 2011).

Correction for instrumental drift has been carried out as follows:

$$
I_{i}^{\mathrm{Sa}}=I_{i}^{\mathrm{raw}}+\left[t-\left(\frac{t_{f}-t_{0}}{2}\right)\right] \frac{1}{k} \sum_{i=1}^{k}\left[m_{\mathrm{std} \_}\right],
$$

where $I_{i}^{\mathrm{Sa}}$ is the intensity of element $i$ in the sample and surrounding background corrected for instrumental drift, $I_{i}^{\text {raw }}$ is the raw intensity of element $i$ in the sample, $t$ indicates the time (in s) of the analysis between the finish time $t_{\mathrm{f}}$ and the start $t_{0}$, and $m_{\text {std } \_i}$ represents the slope of the regression line obtained using NIST612 standard data (Fig. S1, Supplement) acquired for each element during a single ICPMS run executed during a day of analyses where $k$ ICPMS runs are performed. The typical ICPMS instrumental drift observed during a long data acquisition "run" comprised of standards, cleaning, and data acquisition usually comprises between 5 and $8 \%$ per hour, with NIST 612 intensities slightly decreasing with time (see Fig. S1, Supplement).

Each element has been externally calibrated using a set of four custom-made ice standards chosen from a total of five (SLRS-5, SLRS-5_10, ICP-20, NIST1648a, and Water Low), prepared at RHUL from four different standard solutions at different concentrations and different dilutions (Table S1; see the Supplement). All of our ice standards except SLRS-5 were prepared by dilution between 1:10 and $1: 1000$ of the certified reference material with ultrapure $\mathrm{H}_{2} \mathrm{O}(>18 \mathrm{M} \Omega \mathrm{cm})$; we very mildly acidified these solutions with $1 \%$ ultrapure $\mathrm{HNO}_{3}$ to stabilize them before freezing and to align them with the acidity of the ICP1 multielemental standard solution (Sigma-Aldrich), which was the only one originally (before dilution) in $10 \% \mathrm{HNO}_{3}$, unlike all of our other standard solutions.

This external calibration assumes overall comparable ablation characteristics of NGRIP ice and ice standards, which in view of their similar matrix is a satisfactory assumption. Furthermore, using $m / z=17(\mathrm{OH})$ as an internal standard following Reinhardt et al. (2003) is not feasible because the significantly lower sample consumption of UV-LA relative to IR-LA (Müller et al., 2011) does not result in a background-resolved ICPMS signal at $m / z=17$. Ice standards were made in a laminar-flow clean hood (US 10-100, ISO4-5) located in a clean laboratory at RHUL, using an acid-cleaned, custom-made PTFE mould shown in Fig. 2. The mould features two inner volumes, namely one round pool where liquid nitrogen can be used to cool the mould and the innermost volume that uses a polished Pyrex borosilicate glass slide as a bottom surface that can be removed to extract the ice. The procedure to produce homogenous ice standards is as follows.

i. A polyurethane box is filled with $0.5 \mathrm{~L}$ of liquid nitrogen (LN) (Fig. 2b).
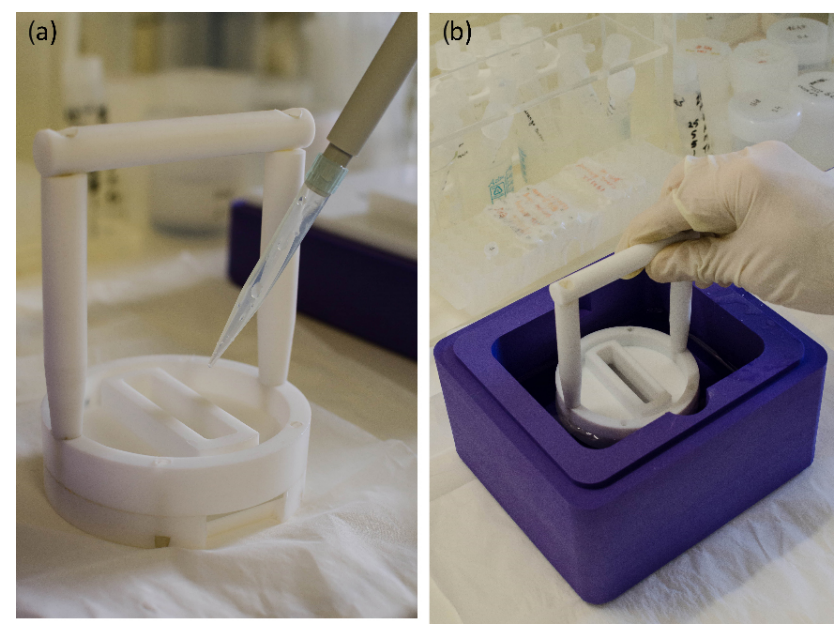

Figure 2. Ice standard preparation at RHUL. (a) $1 \mathrm{~mL}$ of aqueous standard solution is pipetted into the inner volume of a PTFE mould featuring a removable glass surface at the bottom to allow the solution to spread uniformly, creating a thin layer of water. (b) The mould is dipped into liquid nitrogen to instantaneously shock-freeze the solution. This procedure is repeated five times to build up an ice volume by shock-freezing layer by layer of $5 \mathrm{~mL}$ total volume, resulting in an ice volume of approximately $45 \times 10 \times 10 \mathrm{~mm}$. Each ice standard was then surface-cleaned using our PTFE vice before analysis (see text).

ii. $1 \mathrm{~mL}$ of standard solution already prepared (for concentrations, see Table S1, Supplement) is pipetted into the inner volume of the mould, to create a $\sim 2 \mathrm{~mm}$ liquid layer residing on the glass (Fig. 2a).

iii. The entire mould is dipped into the liquid nitrogen, which causes near-instantaneous shock-freezing of the liquid contained in the inner volume (Fig. 2b). The procedure indicated in (ii) and (iii) is then repeated five times to create a volume of ice of $\sim 10 \mathrm{~mm}$ height, built up by shock-frozen layers of standard solution.

This procedure ensures acceptable homogeneity of elements in the ice volume at relative standard deviations (RSDs) of $\sim 10-15 \%$ within a single analysis (Fig. 3), improving on what has been achieved in other UV-LA-ICPMS ice core analyses (Sneed et al., 2015). A standard suspension of NIST1648a has been prepared by carefully weighing $4.92 \mathrm{mg}$ of "Urban Dust" NIST1648 reference material which was subsequently diluted in $100 \mathrm{~mL}$ of ultrapure $(18.2 \mathrm{M} \Omega \mathrm{cm})$ water and $1 \mathrm{~mL}$ of $\mathrm{HNO}_{3}$. The solution then was homogenized through three cycles of $5 \mathrm{~min}$ of mechanical vibration of the container, before being frozen as described in (i)-(iii). Given the NIST1648a average particle size of $5-10 \mu \mathrm{m}$ and the $90 \%$ percentile of $30 \mu \mathrm{m}$, we assume a homogeneous distribution of particles at the scale of the acquisition spot size utilized $(212 \mu \mathrm{m})$. Ice blanks were also produced following the procedure described above by shock-freezing ultrapure $(18.2 \mathrm{M} \Omega \mathrm{cm})$ water; corresponding 


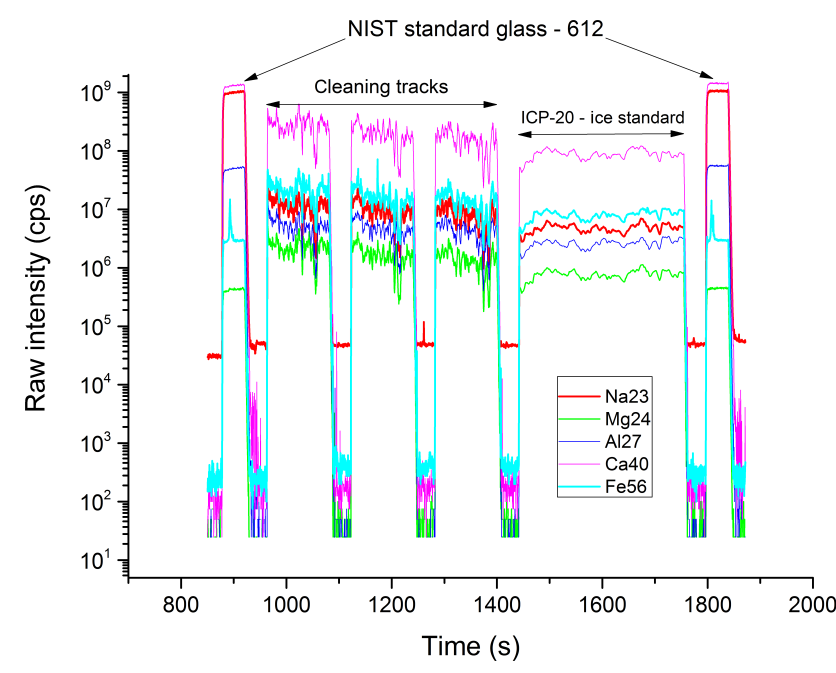

Figure 3. Example of raw intensity data of NIST612 glass (first and last peaks) compared to one of the ice standards prepared for this study (ICP-20). Standard data were acquired following three cleaning runs, and show that the ice standard appears rather homogeneous, with typical RSD values between \pm 10 and $15 \%$. See text for details.

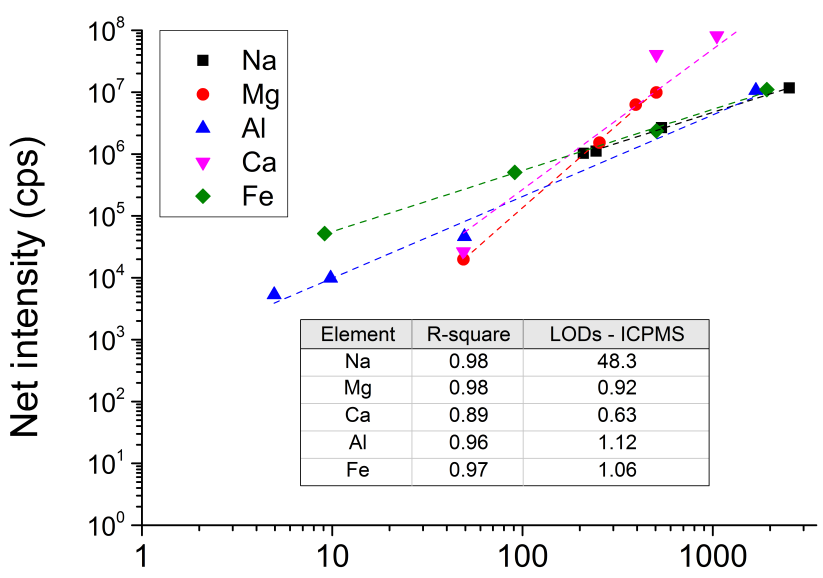

Nominal concentration in reference solution $(\mathrm{ppb})$

Figure 4. Calibration lines for elements under investigation obtained utilizing the ice standards listed in Table S1 (Supplement). LODs indicate limits of detection. See text for details.

UV-LA-ICPMS data show no significant contamination following laser cleaning of the ice surface (see Fig. S2 and Table S1 in the Supplement).

For each element, the slope of the equation of the regression line fitting all four standards in a linear plot has been calculated (together with the corresponding $R^{2}$ value) and utilized to convert net intensities into concentrations. For the sake of display, Fig. 4 shows all regression lines in a log-log plot.

Analyses were carried out using laser tracks which had been preceded by three laser cleaning passages at $25 \mathrm{~Hz}$ with a spot size of $280 \mu \mathrm{m}$ and a speed of $8 \mathrm{~mm} \mathrm{~min}^{-1}$. This was done to remove residual contamination after cleaning with the custom-built vice. Data were acquired at $20 \mathrm{~Hz}$, $212 \mu \mathrm{m}$ spot size, $3 \mathrm{~mm} \mathrm{~min}^{-1}$ speed, and a laser fluence of $\sim 3.5 \mathrm{~J} \mathrm{~cm}^{-2}$. This gives a resolution of approximately $200 \mu \mathrm{m}$ and a cumulative trench depth of $\sim 20 \mu \mathrm{m}$ (estimated by visual imaging and a typical ablation rate per pulse of $0.1 \mu \mathrm{m}$; Müller et al., 2011). Every acquisition run starts and ends with a NIST612 and ICP-20/SLRS-5/NIST1648a track and comprises two parallel tracks, to assess reproducibility. Figure S3 (Supplement) shows raw intensities from two representative parallel ablation tracks running $2 \mathrm{~mm}$ apart along the length of three consecutive samples (depth range: 2691.45-2691.30 m). The tracks show that, for each element, the signal preserves its overall shape in both tracks and concentrations show similar absolute values, with differentiations only observable at sub-mm scale, although significant in a few cases (Fig. S3). For all the samples, the instrumentaldrift-corrected intensities were then averaged between the two tracks and used for calibration. Two-dimensional maps of two different $4 \times 4 \mathrm{~mm}$ cross sections at specific depths were constructed interpolating the values resulting after calibration from the signal generated by static laser drilling $(40 \mathrm{~s})$ on a grid of $12 \times 12$ circular spots of diameter of $128 \mu \mathrm{m}$ at $200 \mu \mathrm{m}$ spacing. The intensities obtained from static drilling were corrected as in Della Lunga et al. (2014).

Limits of detection were calculated as follows:

$\operatorname{LOD}_{i}^{\mathrm{Sa}}=\left(\frac{c_{i}^{\mathrm{std}}}{I_{i}^{\mathrm{std}}-I_{i}^{\mathrm{bkg}}}\right) 3 \sigma_{i}^{\mathrm{bkg}}$,

where $c_{i}^{\text {std }}$ is the concentration (in ppb) of the element $i$ in the standard, $\sigma_{i}^{\mathrm{bkg}}$ is the standard deviation of the background for an element $i, I_{i}^{\text {std }}$ is the averaged intensity of the element $i$ in the sample, and $I_{i}^{\mathrm{bkg}}$ is the averaged intensity of the background of element $i$. The values obtained for this study are listed in Table S1 (see the Supplement) and range between $0.6 \mathrm{ppb}(\mathrm{Ca})$ and $48 \mathrm{ppb}(\mathrm{Na})$. The $\mathrm{Na}$ LOD value is higher due to a typical elevated (LA-ICPMS) sodium background, exaggerated by using routinely NIST61x glasses $\left(14 \pm 0.1 \% \mathrm{~m} \mathrm{~m}^{-1} \mathrm{Na}_{2} \mathrm{O}\right.$; Jochum et al., 2011) for other LA work. Therefore, Na data present several gaps and are shown here only in an overview figure (Fig. 5), mainly to allow comparison with existing CFA-Na data (Vallelonga et al., 2012). Uncertainties have been estimated using the following equation:

$\sigma_{\text {tot }}=\sqrt{\left(\sigma_{\text {nist_std }}\right)^{2}+\left(\sigma_{\text {ice_std }}\right)^{2}+\left(\sigma_{\text {id }}\right)^{2}+\left(\sigma_{\text {ice_calib }}\right)^{2}}$,

where $\sigma_{\text {nist_std }}$ and $\sigma_{\text {ice _std }}$ represent the relative standard error of the signal acquired during a single run for NIST 612 and the selected ice standard respectively, while $\sigma_{\text {id }}$ and $\sigma_{\text {ice_calib }}$ represent the standard errors related to the instrumental drift correction and the calibration, and are typical for each element. The total uncertainty $\sigma_{\text {tot }}$ is on average about $\pm 16 \%, \sigma_{\text {ice_std }}$ contributing $90 \%$ to this value. 


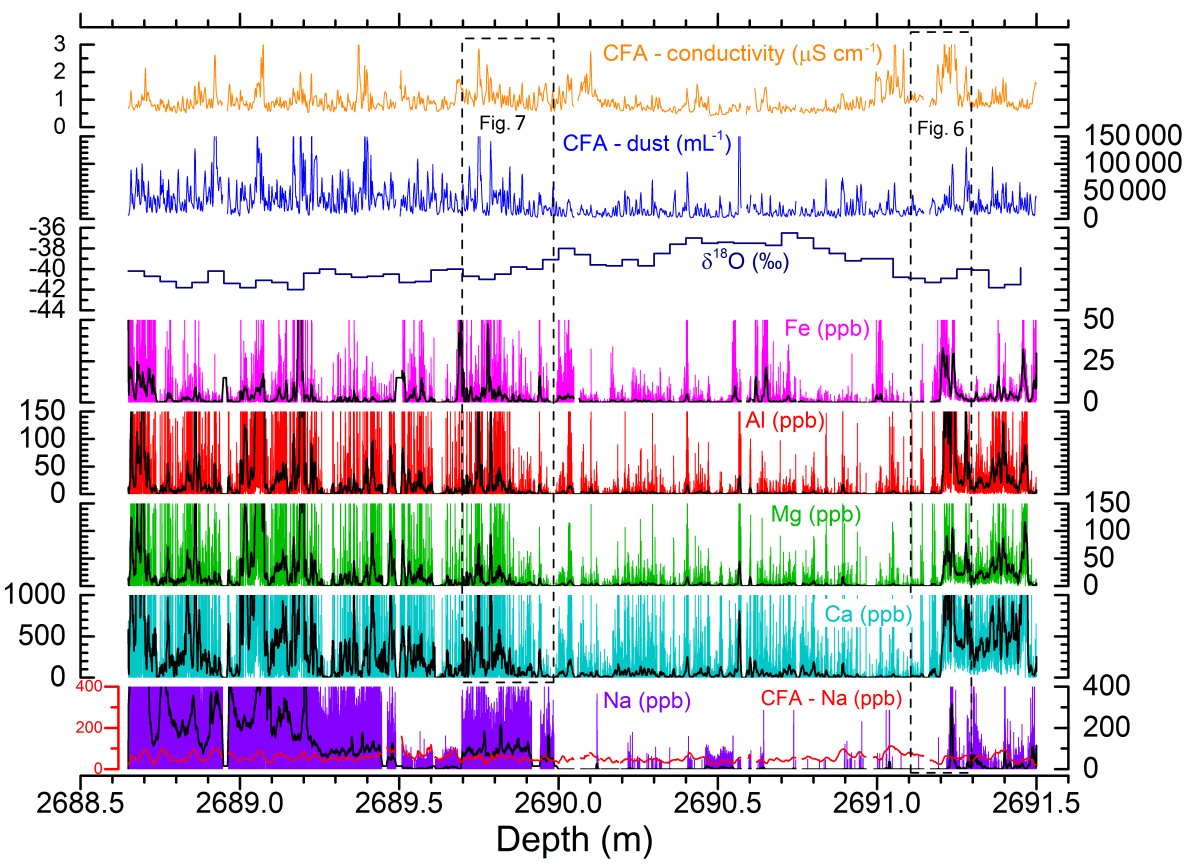

Figure 5. Cryo-cell LA-ICPMS element concentration profiles of $\mathrm{Na}, \mathrm{Mg}, \mathrm{Al}, \mathrm{Ca}$, and $\mathrm{Fe}$ and corresponding $\mathrm{Na}, \delta^{18} \mathrm{O}$, and $\mathrm{CFA}$ dust profiles at 3.5, 50, and $1.5 \mathrm{~mm}$ resolution respectively (the latter three from Vallelonga et al., 2012) across $2.85 \mathrm{~m}$ of the NGRIP ice core that spans from approximately 85090 to 84860 a b2k $( \pm 20$ a) and contains GI-21.2. The coloured lines are individual LA-ICPMS data points; black lines represent the adjacent-element moving average (period 200). It should be noted that cryo-cell LA-ICPMS Na LOD is 48.3 ppb, which renders most of the interstadial and some stadial $\mathrm{Na}$ data undetectable. Overall, $\mathrm{Na}$ is mainly shown to allow some comparability with existing CFA Na data (Vallelonga et al., 2012). See text for details.

\section{Results}

Results of cryo-cell UV-LA-ICPMS measurements of Na, $\mathrm{Mg}, \mathrm{Al}, \mathrm{Ca}$, and $\mathrm{Fe}$ concentrations across the analysed section of GI-21.2 and GS-21.2 are displayed in Figs. 5-8 (data available at doi:10.1594/PANGAEA.875711). For each millimetre of ice analysed, we obtain 40 data points, given the chosen $x-y$ scan speed and the ICPMS sweep time. The resolvable spatial resolution is $\sim 200 \mu \mathrm{m}$ given the interplay between spot size, stage speed, ICPMS dwell time, and laser repetition rate, making down-sampling of individual data points in the form of a moving average necessary. The matching $\delta^{18} \mathrm{O}$ profile (Vallelonga et al., 2012) at $50 \mathrm{~mm}$ resolution shows a $\sim 4 \%$ o shift to more positive values between depths of 2691.15 and $2690.70 \mathrm{~m}$, representing the rapid warming into GI-21.2, after which $\delta^{18} \mathrm{O}$ gradually returns to pre-warming values (Figs. 1 and 5). The element profiles acquired via cryo-cell LA-ICPMS show a similar pattern (Fig. 5). The deepest $300 \mathrm{~mm}$ of our profile for all of the elements (depth range 2691.50-2691.20 m) show relatively high concentrations and several peaks. An abrupt drop is observable around a depth of $2691.20 \mathrm{~m}$, with minor differences between each element. The variation is very sharp and happens over a space of approximately $10 \mathrm{~mm}$, which, at this depth, represents approximately 1 year (Fig. 6). Towards shallower depths, most of the elements show, after some characteristic variability, a minimum in concentrations up to a depth of $2690.10 \mathrm{~m}$. At these depths concentrations often fall below LODs, having the lowest values of the entire section. From depth $2690.30 \mathrm{~m}$ onwards, $\delta^{18} \mathrm{O}$ gently decreases from approximately -37.5 to $-41 \%$, representing the cooling phase. In this part, elemental concentrations increase gradually, and the patterns present a higher degree of variability.

Overall, the record can be divided into three main intervals: (i) the deepest $300 \mathrm{~mm}(2691.50-2691.20 \mathrm{~m})$ show relatively high concentrations for every element, with average values of $54,490,48,60$, and $15 \mathrm{ppb}$ for $\mathrm{Na}, \mathrm{Ca}, \mathrm{Mg}, \mathrm{Al}$, and Fe respectively. Around the depth of $2691.20 \mathrm{~m}$ an abrupt decrease in all elemental concentrations is observable, with values dropping by a factor of $\sim 10$ to average concentrations of $15,1.3,1.4$, and $1.0 \mathrm{ppb}$ for $\mathrm{Ca}, \mathrm{Mg}, \mathrm{Al}$, and $\mathrm{Fe}$ respectively (Na is well below LOD). The second section (ii) is characterized by low values during the interstadial phase from 2691.20 to $2690.00 \mathrm{~m}$, followed by (iii) a gradual increase in concentrations from depth $2690.00 \mathrm{~m}$ to depth $2688.65 \mathrm{~m}$, with most of the elements showing recurring short-term variability at multiannual timescales with more than 10 -fold concentration oscillations.

Figures 6 and 7 show in detail two 200 and $300 \mathrm{~mm}$ zooms of section (iii). In Fig. 6, we can also observe a few minor differences between the respective elemental profiles: at a depth 


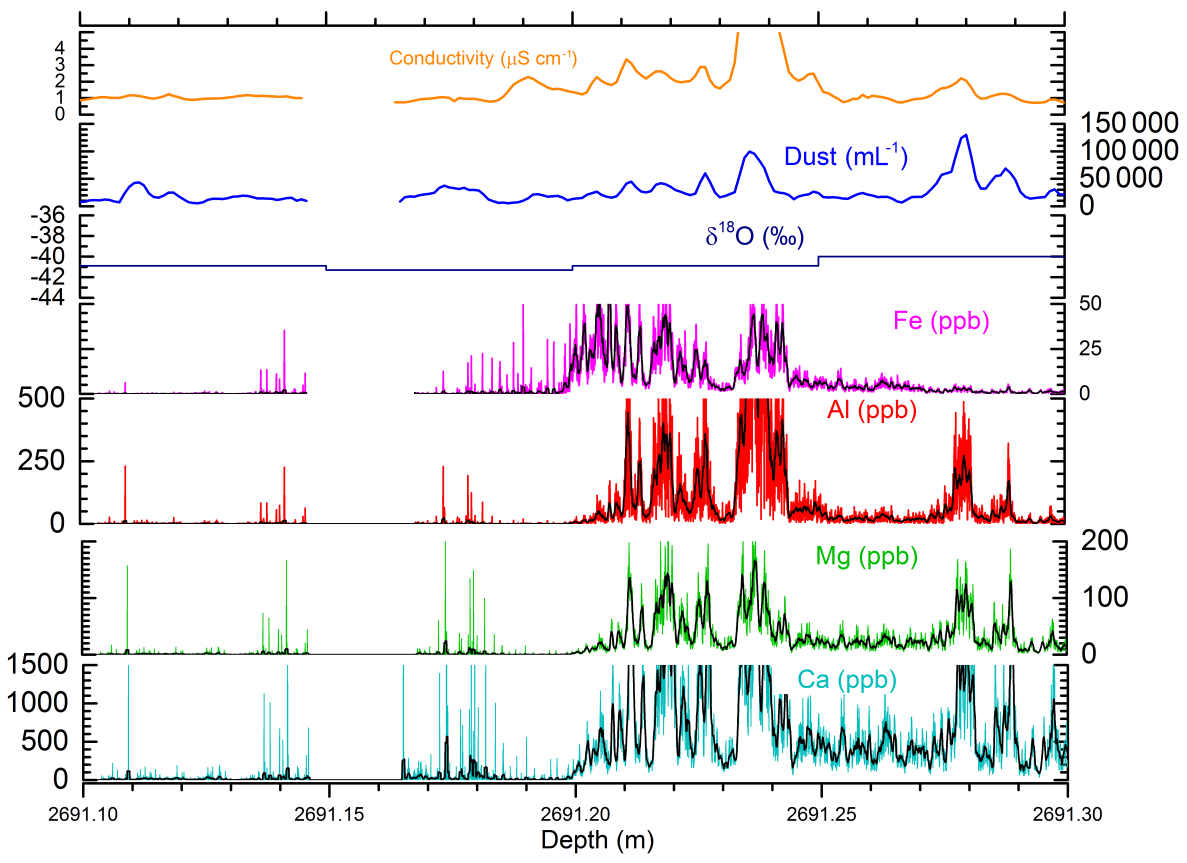

Figure 6. Zoomed-in cryo-cell LA-ICPMS profiles of a $200 \mathrm{~mm}$ window from the deepest part of the GI-21.2 section (cold-warm transition), analysed for the most significant elements and spanning about 2 decades around $85.1 \mathrm{kab} 2 \mathrm{k}$. Coloured lines represent LA data; black lines are 30-point moving averages. A switch between stadial and interstadial typical concentrations is observable around $2691.20 \mathrm{~m}$, happening over a space of just $\sim 10 \mathrm{~mm}$. Conductivity and CFA dust are from Vallelonga et al. (2012).

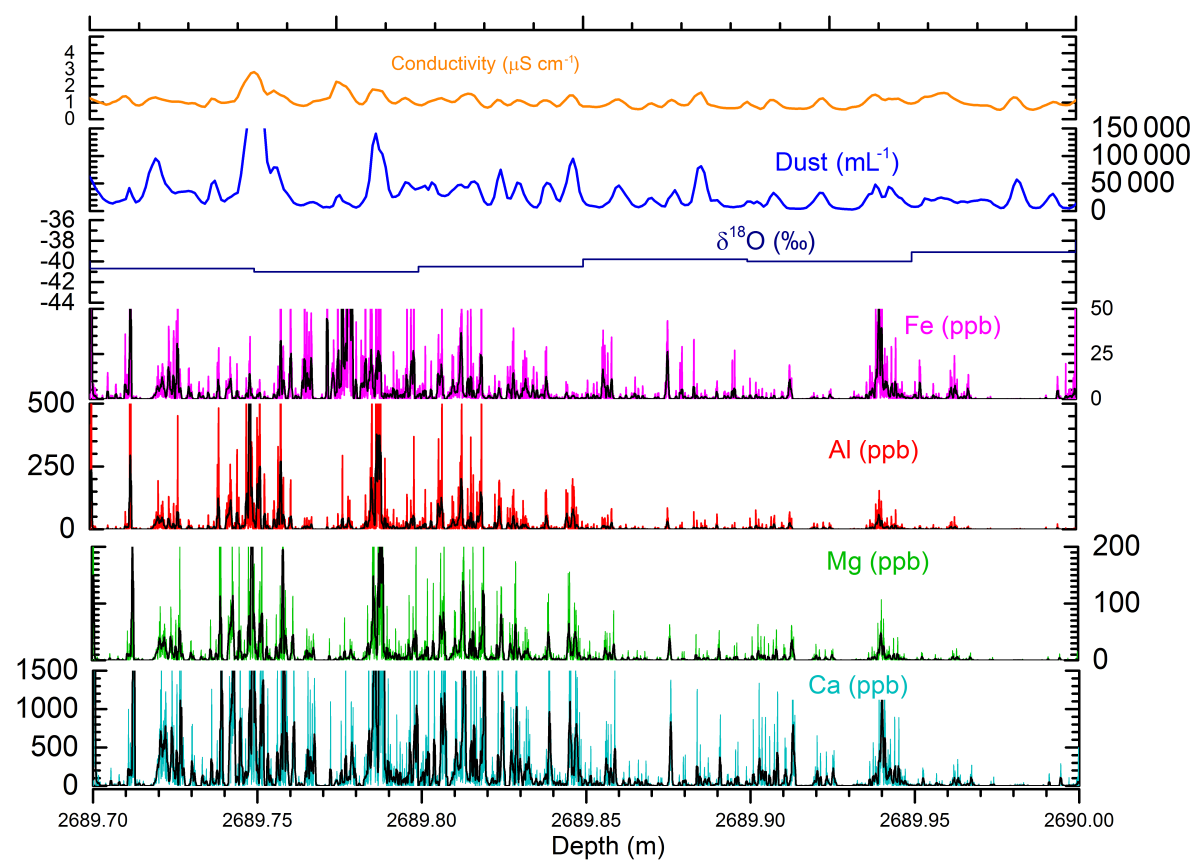

Figure 7. Zoomed-in cryo-cell LA-ICPMS profiles of a $300 \mathrm{~mm}$ window from the middle part of the GI-21.2 section analysed for the most significant elements and spanning about 2 decades around $85.0 \mathrm{ka}$ b2k (cold-warm transition). Coloured lines represent LA data; black lines are 30-point moving averages. A gradual increase in dustiness is observable starting from a depth of $2689.95 \mathrm{~m}$ and going towards shallower depths, representing the GI-21.2 - GS-21.2 transition, which in this case takes place over the space of $\sim 150 \mathrm{~mm}$. Conductivity and CFA dust are from Vallelonga et al. (2012). 


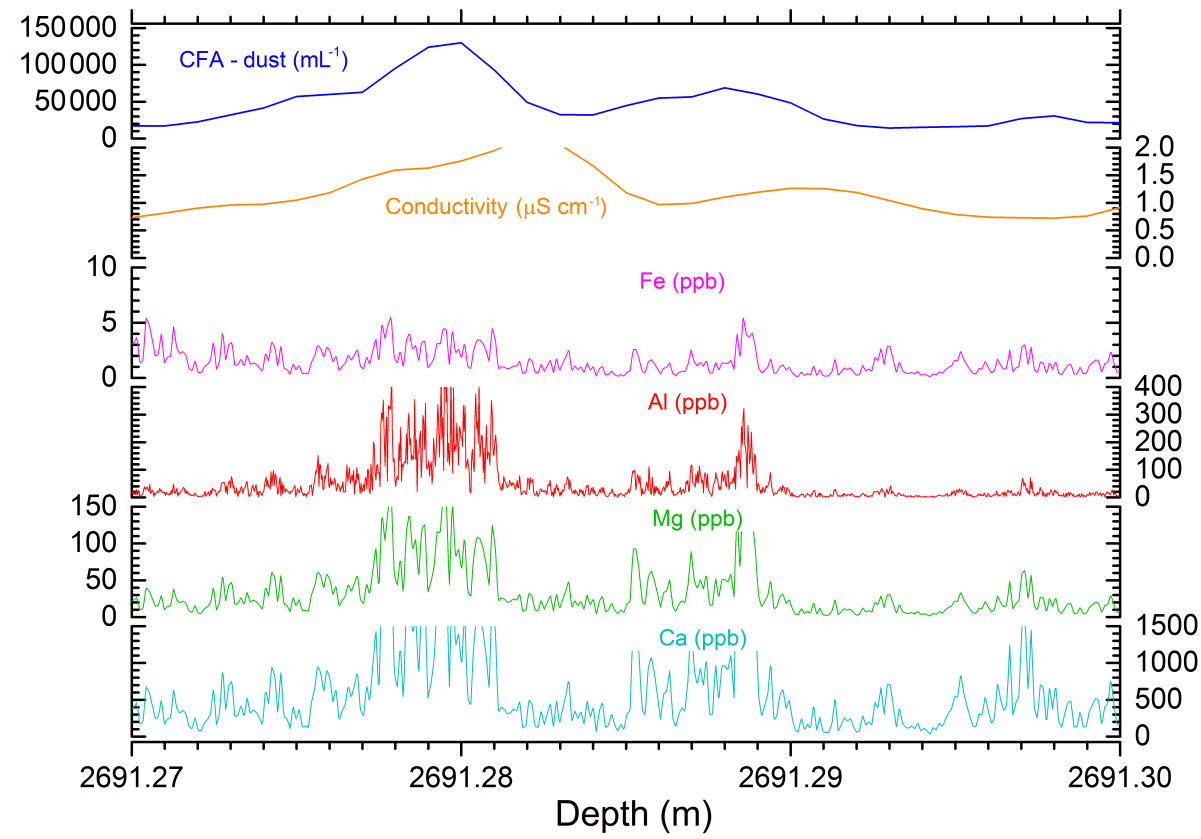

Figure 8. CFA conductivity, CFA dust, LA-Fe, LA-Ca, LA-Al, and LA-Mg direct comparison across a detailed $3 \mathrm{~cm}$ zoom. In this case, laser-ablation data have not been smoothed. Conductivity and CFA dust are from Vallelonga et al. (2012). The profiles show sub-annual variations that contribute to the CFA annual signal.

of $2691.28 \mathrm{~m}$, a clear peak in $\mathrm{Ca}, \mathrm{Mg}$, and $\mathrm{Al}$ is not mirrored by $\mathrm{Fe}$; furthermore, $\mathrm{Al}$ and $\mathrm{Mg}$ drop in concentration before $\mathrm{Ca}$ and especially $\mathrm{Fe}$, whose decrease occurs at a shallower depth by approximately 3 to $5 \mathrm{~mm}$. Similarly we observe a peak in $\mathrm{Ca}, \mathrm{Mg}$, and $\mathrm{Al}$ at a depth of $2689.83 \mathrm{~m}$ (Fig. 7) that is much less pronounced in the $\mathrm{Fe}$ profile, whereas the opposite feature is seen at a depth of $2689.78 \mathrm{~m}$ (Fig. 7), where Fe presents a very pronounced peak that is not matched by $\mathrm{Al}, \mathrm{Mg}$, and $\mathrm{Ca}$. Figure 8 shows a $30 \mathrm{~mm}$ zoom comprising two to three annual layer peaks identified in both CFA and LA data. LA profiles show the complex structure of a single annual peak to which several minor peaks contribute. These peaks may reflect single storm events.

Figures 9 and 10 show a collection of maps of calibrated concentrations of the elements under investigation from a $4 \times 4 \mathrm{~mm}$ cross section at depths of 2689.78 and $2689.65 \mathrm{~m}$. These sections were chosen specifically from depths where concentrations were high and presented a considerable degree of small-scale variability, as inferred from our laserablation profiles.

\section{LA-ICPMS-CFA data comparison}

For comparison, our cryo-cell LA-ICPMS data have been plotted together in Figs. 5-8 with previously published CFA results from the same NGRIP depths (Vallelonga et al., 2012). In contrast to the cryo-cell LA-ICPMS resolution of $\sim 0.2 \mathrm{~mm}$, the CFA profiles of $\mathrm{Na}, \delta^{18} \mathrm{O}$, CFA dust, and con- ductivity have resolutions of $3.5,50,1.5$, and $1.5 \mathrm{~mm}$ respectively. The two datasets show some similarities: between a depth of 2691.50 and $2691.20 \mathrm{~m}$, the dust, and partly also the conductivity profiles, present relatively high values, similar to what is observed for our elemental proxies, typical of the stadial GS-22 phase. At 2691.20 CFA dust and LA data are both characterized by a decrease in concentrations, although the LA data show much clearer and abrupt features, marking the start of the GI-21.2 warm phase. Furthermore, minima for the entire section are located between depths of 2690.95 and $2690.15 \mathrm{~m}$ in both datasets. Also, both datasets agree in the shallowest part of the section, showing a more increasing trend starting at $2690.00 \mathrm{~m}$.

In Fig. 5, Na data from CFA and LA-ICPMS analyses have been plotted together on the same $y$-scale. The two datasets show analogous patterns and broadly comparable average values in part of the section, such as between 2690.00 and $2689.25 \mathrm{~m}$ (70 and $67 \mathrm{ppb}$ in the CFA and LA-ICPMS profiles respectively). However, LA-ICPMS-Na characteristically is more variable and differs from CFA data in the intervals 2689.20-2688.65 and 2691.5-2691.5 m, where LAICPMS-Na is either higher or lower relative to CFA-Na respectively. This, although it seems to indicate that there is no overall systematic shift between the two techniques, highlights the difficulty of LA-ICPMS in detecting reliable absolute concentrations for $\mathrm{Na}$, even if the patterns are preserved. This problem could arise from ICPMS-Na background variability, typically very high from day to day, affecting the signal detection and calibration. Moreover, the tendency of 

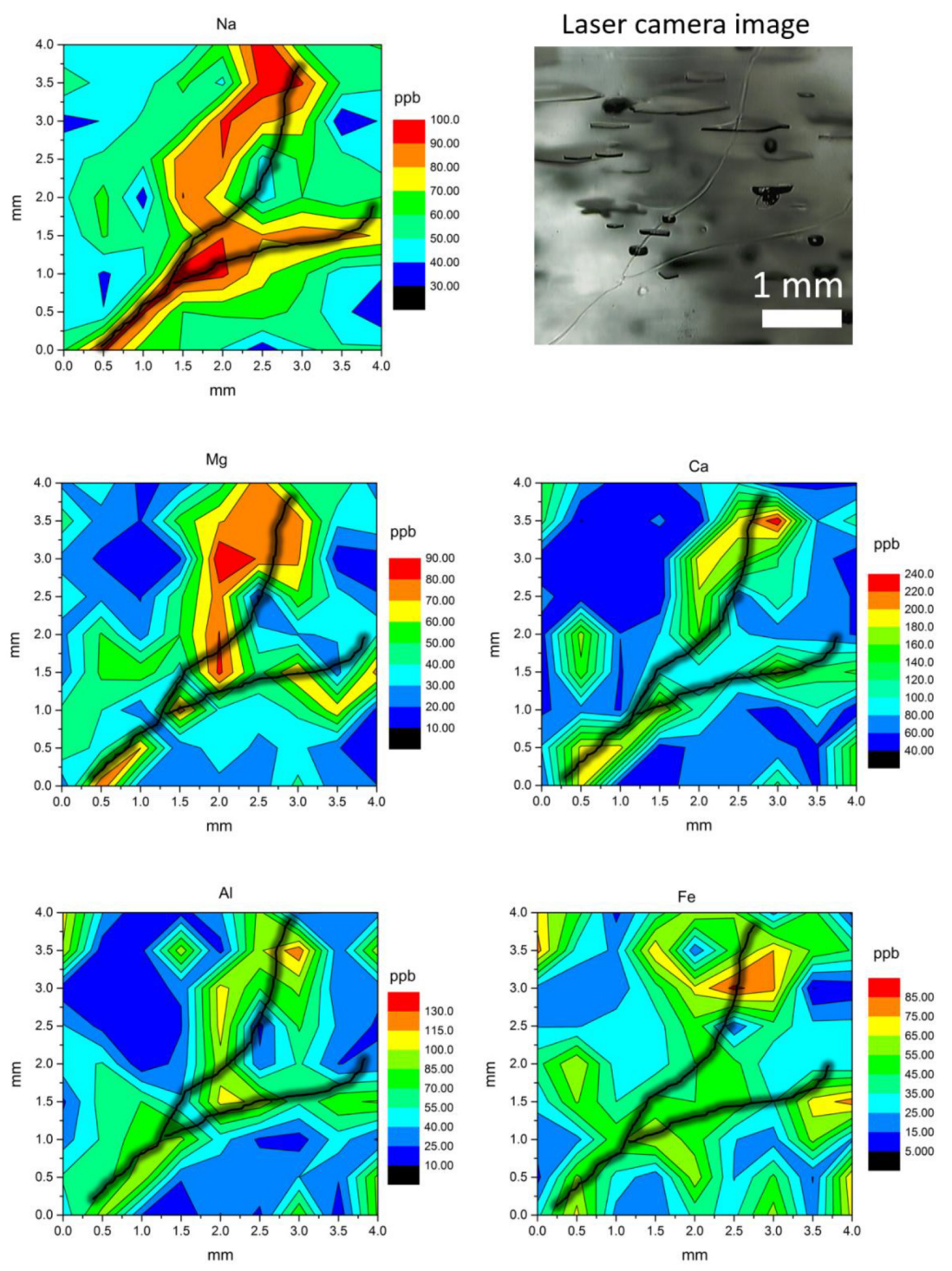

Figure 9. Two-dimensional maps of calibrated concentrations of elements under investigation ( $\mathrm{Na}, \mathrm{Mg}, \mathrm{Ca}, \mathrm{Al}, \mathrm{Fe}) \mathrm{across}$ a $4 \times 4$ mm cross section with an overlaid grain boundary net in black as observed in transmitted light (upper right) from a depth of $2689.78 \mathrm{~m}$.

Na to show higher concentrations in the proximity of grain boundaries and junctions complicates more the detection of $\mathrm{Na}$ via LA, since laser-ablation tracks scan across several boundaries and junctions several times in a single sample, introducing a factor of differentiation that is also reflected in our calibration since it reduces the homogeneity of our ice standards. Therefore, LA-Na profiles still do not agree satisfactorily with CFA-Na and caution must be applied in the interpretation process.

As a further test, we compared the cryo-cell UV-LAICPMS data acquired in the frozen state with results from the same three NGRIP samples analysed via solution ICPMS after melting $(10 \mathrm{~mL})$. The three samples correspond to three different depths in the immediate vicinity of GI-21.2 and represent a wide range of concentrations: early GS-22 (sam- ple 4940A11), late GS-22 (sample 4900A3), and GI-21.1 (sample 4882B4). Results show that calibrated solution data are consistent with our LA-ICPMS data and differ by 5 $20 \%$, which is essentially within our margin of error. Sample 4882B4, representing the last part of GS-21.2, shows the lowest concentrations amongst the three samples and also the consistently largest differences between solution and laser data (see Fig. S4 in the Supplement).

\section{Origin of the laser-ablation elemental signal}

The intensity of the LA signal associated with a certain mass / charge ratio, characteristic of one element, is built up by two different contributions: one from soluble ions present 



Figure 10. Two-dimensional maps of calibrated concentrations of elements under investigation $(\mathrm{Na}, \mathrm{Mg}, \mathrm{Ca}, \mathrm{Al}, \mathrm{Fe}) \mathrm{across}$ a $4 \times 4$ mm cross section with an overlaid grain boundary net in black as observed in transmitted light (upper right) from a depth of $2689.65 \mathrm{~m}$.

in the ice matrix and the other one from dispersed insoluble mineral particles containing the element in their structure. Micro-particles in the NGRIP ice core have a mean grain size between 1 and $2 \mu \mathrm{m}$ (Ruth et al., 2003) and therefore are too small to be identified unequivocally with our laser camera. Visual inspection of the sample before, after, and during ablation indicated that no residual spatter of the ablation process was deposited back onto the ice surface after the laser hit the sample, indicating a complete digestion of the material removed by the ablation pulses. This suggests that no fractionation between soluble and insoluble particles takes place by effect of the laser sampling.

We investigated the spatial distribution of $\mathrm{Na}, \mathrm{Mg}, \mathrm{Al}, \mathrm{Ca}$, and Fe over two small horizontal planes (i.e. perpendicular to the core length axis) by analysing 2-D maps of concentrations across two specific cross sections (Figs. 9 and 10). These sections were constructed by interpolating several ac- quisition points obtained via static laser drilling. Figures 9 and 10 both show concentrations spanning over a range of several tens of ppb for each element across the entire sections. The cross sections intersect few grain boundaries and junctions (as observable in the laser camera image). The grain boundary net has been overlaid in black onto the elemental maps and shows that, in most of the cases, high concentration areas are located in the proximity of boundaries and junction, broadly mimicking their pattern. In both cases, these patterns are somehow clearer for elements like $\mathrm{Na}$ and $\mathrm{Mg}$, related to sea salt, and become less defined going from $\mathrm{Ca}$ to $\mathrm{Al}$ and $\mathrm{Fe}$. This might be associated with the fact that the elemental signal has a relative increasing contribution from micro-particles going from $\mathrm{Ca}$ to $\mathrm{Al}$, to $\mathrm{Fe}$, whereas the contribution from micro-particles to the $\mathrm{Na}$ and $\mathrm{Mg}$ signal is minimal. This would also suggest that micro-particles are slightly less inclined to be aligned on boundaries and junc- 
tions compared to soluble impurities and therefore generate a less defined pattern of concentrations on our maps.

\section{Discussion}

Our fully quantitative calibration of cryo-cell UV-LAICPMS net count rates to elemental concentrations is presented here for the first time. We have succeeded in producing suitably homogeneous ice standards $( \pm 10-15 \%$ RSD, Fig. 3) from four different solutions at known elemental concentrations and one frozen suspension at different dilutions. This represents an improvement to what has previously been achieved in ice standard preparation (Reinhardt et al., 2003; Wilhelm-Dick, 2008; Sneed et al., 2015). The correlation between the elemental concentrations in the standards and the resulting net signals from cryo-cell LA-ICPMS (in counts per second, cps) is good and follows the expected linear relationship (Fig. 4), with $R^{2}$ values ranging from 0.89 to 0.98 .

The removal of contamination is ensured not only by surface-smoothing executed via a "major-element free" $\mathrm{ZrO}_{2}$ blade (Della Lunga et al., 2014), but also by laser cleaning performed three times before each acquisition. Its effectiveness can be demonstrated using ice blanks (see Fig. S2 in the Supplement). The overall uncertainty estimation derived from analysis and calibration gives an average value of $\pm 16 \%$, which has to be considered acceptable for ice core analysis, where elemental concentrations are typically in the low ppb range and variability usually covers more than 1 order of magnitude.

Figure 5 shows remarkably large concentration variations of all the elements, which can drop and rise by a factor of $\sim 10$ in as short a distance as $10 \mathrm{~mm}$, representing approximately 1 year at this depth and confirming that dust proxies $(\mathrm{Na}, \mathrm{Mg}, \mathrm{Al}, \mathrm{Ca}, \mathrm{Fe})$ do react to natural abrupt climate change events at timescales much shorter than the duration of short-lived interstadials such as GI-21.2. The pattern of all the elements shows high values in the deepest part before abruptly decreasing approximately by a factor of 10 down to few ppb or even ppt (below LOD). Concentrations stay low during the GI-21.2 interstadial part and then rise again more gradually, showing much more pronounced oscillations, with a further increase to higher values towards the end of the section, where concentrations return to the typical high stadial concentrations. Overall, the general pattern of LA-ICPMS proxies agrees well (Figs. 5, 6, and 7) with the previously published dataset of CFA analysis for the same NGRIP depth range (Vallelonga et al., 2012).

The slightly different pattern between $\delta^{18} \mathrm{O}$ and elemental proxies has to be expected as the resolution of the two records is different, namely $50 \mathrm{~mm}$ and $\sim 200 \mu \mathrm{m}$ respectively. However, LA data seem to confirm that elemental "dust" proxies react before $\delta^{18} \mathrm{O}$ to the GI-21.2 warming onset, showing a drop in concentration at $2691.20 \mathrm{~m}$, thus $100 \mathrm{~mm}$ before the main oxygen rise at $2691.10 \mathrm{~m}$, extending and confirming the observations by Thomas et al. (2009).

CFA analysis of the same section shows similar features to what we observe in UV-LA data, especially regarding the transitions from GS-22 to GI-21.2 and from GI-21.2 to GS-21.2, which occur approximately within the same depth range in both cases $(2691.20,2690.10-2689.90 \mathrm{~m})$. However, elemental proxies (Fig. 5) show much clearer features in terms of abruptness and amplitude of oscillations compared to CFA data, and a more pronounced variability at the $\mathrm{cm}$ scale (Figs. 6, 7) that is often related to sub-annual variations, observable also in Fig. 8. This may be related to single storm events that could have originated from different dust sources, resulting in a variation in the elemental ratios (especially $\mathrm{Ca}-\mathrm{Al}$ vs. $\mathrm{Fe}$ ) at short timescales, as observed in Figs. 6 and 7.

Most of the differences between CFA and LA-ICPMS proxies are observed at a small scale and are mainly influenced by few factors, the first of which is the effect of sample volume. In fact, we estimate that every LA-ICPMS data point corresponds to $\sim 120 \mathrm{ng}$ of ablated ice (based on scanning speed and ice crater depth), whereas the CFA sampling resolution is about $0.1-1 \mathrm{~g}$ for each data point (Vallelonga et al., 2012). This introduces a difference in the sampling volume between the two datasets that can also be influenced by surface effects and especially by the wavy nature of layers at this scale and core depth. This is particularly important for $\mathrm{Na}$, whose lateral variability induced by any nonhorizontal layering is also affected by diffusion of $\mathrm{Na}$ that has been observed at this depth, resulting in a smoothing of the CFA annual signal (Vallelonga et al., 2012). Furthermore, the CFA insoluble dust data presented here refer to measurements of particles of size $>1 \mu \mathrm{m}$ and therefore do not account for insoluble impurities of sub-micron size (Vallelonga et al., 2012).

The elemental maps shown in Figs. 9 and 10 demonstrate that, at sub-cm scale, the concentrations of impurities are strongly influenced by the presence of boundaries and junctions even when considering horizontal planes, whose original impurity input is assumed to be roughly identical. This introduces a main source of differentiation between LA and CFA sampling and can account for some of the small-scale variability we observe in the LA profiles. This is again particularly relevant for element-like $\mathrm{Na}$ and $\mathrm{Mg}$, whose 2-D distribution seems to follow closely the grain boundary net, presenting higher concentrations in the proximity of boundary and junction. On the other hand, "dust" proxies such as $\mathrm{Ca}, \mathrm{Al}$, and Fe do not show such a closer overlap of high intensity and presence of boundaries or junctions, possibly as a result of being increasingly associated with insoluble microparticles dispersed in the ice matrix, which indeed constitutes the CFA-dust signal. This would suggest that micro-particles in the ice matrix are less inclined to reside on boundaries and junctions compared to soluble ions, which is consistent with previous studies of deep ice cores (Della Lunga et al., 2014; 
Eichler et al., 2017). As a result, the averaging of the LA signal between two or more parallel tracks spaced by a few millimetres is not only desirable, but necessary.

Our LA-ICPMS data suggest that dust and sea-salt proxies undergo extremely abrupt, namely sub-annual, variations during abrupt climatic change, representing most of the drop/rise in phase with CFA data from the same depth range (Figs. 5, 6, and 7).

As previously observed by Steffensen et al. (2008) and Fuhrer et al. (1999) in the NGRIP and GRIP record for the much shallower GI-1 and GI-3 respectively, the variations of insoluble dust and $\mathrm{Ca}^{2+}$ concentrations can occur abruptly at a yearly scale for warming transitions. In contrast, for the cooling phase, the interstadial to stadial switch takes place more slowly and through several oscillations. This is compatible with the cryo-cell LA-ICPMS data observed in Fig. 5, extending these patterns to one of the oldest and shortest interstadial-stadial transitions in the NGRIP record. Any mechanism responsible for these changes must be capable of producing a series of extremely abrupt shifts, and must be able to switch on and off very quickly.

A plausible explanation for short precursor-type events such as GI-21.2 could arise from a reorganization of atmospheric circulation at mid-high latitudes in the Northern Hemisphere. This enhances the mobilization at the dust sources (i.e. Asian deserts), as proposed by Fuhrer et al. (1999), and increases the residence time of particles in the atmosphere, which can account for most of the changes in concentration of proxies observable for GI-21.2. GCM simulations (Kutzbach et al., 1993) showed that during the LGM, storms strengthen their intensity and changed their trajectory, originating further south and changing the pressure regime over central Asia. Even a very small increase in the maximum wind speed during episodic storms could have overtaken the threshold value for mobilization of particles of a certain size (Gillette and Passi, 1988). The first signs of the rapid warming could therefore be coeval with a decrease in $\mathrm{Ca}, \mathrm{Al}, \mathrm{Mg}$, and $\mathrm{Fe}$ concentrations as a result of wetter conditions in the Asian dust-source areas, where dust uplift was reduced by the increasing humidity and washout following an intensification of precipitation. A rapid change in atmospheric transport patterns and the relative variation in dust sources would also explain sporadic changes in elemental ratios (e.g. $\mathrm{Fe} / \mathrm{Ca}, \mathrm{Fe} / \mathrm{Al}$ ), which can be identified in our profiles (Figs. 6 and 7).

\section{Summary and conclusions}

Using cryo-cell UV-LA-ICPMS, we obtained $2.85 \mathrm{~m}$ of dust profiles ( $\mathrm{Na}, \mathrm{Mg}, \mathrm{Ca}, \mathrm{Fe}, \mathrm{Al}$ ) from $85 \mathrm{ka}$-b2k-old NGRIP ice covering the GS-22-GI-21.2-GS-21.2 transitions at a resolution of $\sim 200 \mu \mathrm{m}$, which corresponds roughly to 50 data points per year. Quantification of LA-ICPMS signals was possible using a set of five external ice standards carefully produced at RHUL, which proved to be homogeneous at the $\sim 15 \%$ level. Our results for the short-lived GS-22-GI-21.2GS-21.2 transition show that dust proxies vary by up to $\sim 10$ fold in concentration at a scale of $\sim 1$ year, showing abrupt drops due to rapid warming also in the deepest (and oldest) part of the NGRIP record, similarly to what was previously observed for GI-3 and GI-1 (Fuhrer et al., 1999; Steffensen et al., 2008). During the rise that corresponds to the cooling transition, concentrations do not vary sharply, but gradually follow an increasing trend characterized by more than one oscillation. The comparison of cryo-cell LA-ICPMS profiles with CFA data of $\mathrm{Na}$, dust, and conductivity corroborates the results, showing that cryo-cell LA-ICPMS profiles present more variability and a larger frequency of high-concentration peaks across the entire record. We suggest that wetter conditions at Asian sources could have abruptly lowered dust uplift and increased the washout during GI-21.2, when atmospheric circulation over Asian deserts was weaker. This would have resulted in a reduction of transport efficiency and therefore a rapid decrease in dust available to Greenland at short timescales. At the onset of the following cooling period, the end of the wet conditions together with an increase in wind speed and storminess above a threshold level allowed uplift of more particles, which explains the subsequent rise in concentrations of dust to pre-warming levels.

Data availability. The data for this paper are available at doi:10.1594/PANGAEA.875711.

\section{The Supplement related to this article is available online at doi:10.5194/tc-11-1297-2017-supplement.}

Author contributions. Damiano Della Lunga designed the experiment, performed the analysis, interpreted the data, and wrote the manuscript. Wolfgang Müller helped in designing the experiment, performing the analysis and the data interpretation, and editing the manuscript. Sune Olander Rasmussen and Anders Svensson contributed to the designing of the experiment, the sample preparation, the data interpretation, and editing the manuscript. Paul Vallelonga provided CFA data for comparison, helped with the data interpretation, and edited the manuscript.

Competing interests. The authors declare that they have no conflict of interest.

Acknowledgements. This work has been supported by a RHUL studentship granted to Damiano Della Lunga, with the analytical costs being co-funded initially via a research grant from Resonetics LLC \& Laurin Technic to Wolfgang Müller, and subsequently via a postdoctoral grant from Laurin Technic and Australian Scientific Instruments (ASI) to both Damiano Della Lunga and Wolfgang Müller. The authors would like to thank Jerry Morris for continuing 
invaluable technical support at RHUL. Initial discussions with Michael Kriews and Dorothee Wilhelms-Dick helped to improve the methodology of ice standard preparation.

Edited by: M. van den Broeke

Reviewed by: two anonymous referees

\section{References}

Berglund, M. and Wieser, M. E.: Isotopic compositions of the elements 2009 (IUPAC Technical Report), Pure Appl. Chem., 83, 397-410, 2011.

Bigler, M., Svensson, A., Kettner, E., Vallelonga, P., Nielsen, M. E., and Steffensen, J. P.: Optimization of high-resolution continuous flow analysis for transient climate signals in ice cores, Environ. Sci. Technol., 45, 4483-4489, 2011.

Capron, E., Landais, A., Chappellaz, J., Schilt, A., Buiron, D., Dahl-Jensen, D., Johnsen, S. J., Jouzel, J., Lemieux-Dudon, B., Loulergue, L., Leuenberger, M., Masson-Delmotte, V., Meyer, H., Oerter, H., and Stenni, B.: Millennial and sub-millennial scale climatic variations recorded in polar ice cores over the last glacial period, Clim. Past, 6, 345-365, doi:10.5194/cp-6-3452010, 2010.

Della Lunga, D., Muller, W., Rasmussen, S. O., and Svensson, A.: Location of cation impurities in NGRIP deep ice revealed by cryo-cell UV-laser-ablation ICPMS, J. Glaciol., 60, 970-988, 2014.

Della Lunga, D., Müller, W., Rasmussen, S. O., Svensson, A. M., and Vallelonga, P.: Major elemental concentrations from NGRIP ice core across the interstadial period GI-21.2. doi:10.1594/PANGAEA.875711, Supplement to: Della Lunga, D., et al.: Calibrated cryo-cell UV-LA-ICPMS elemental concentrations from NGRIP ice core reveal abrupt, sub-annual variability in dust across the interstadial period GI-21.2, The Cryosphere, 2017.

Eichler, J., Kleitz, I., Bayer-Giraldi, M., Jansen, D., Kipfstuhl, S., Shigeyama, W., Weikusat, C., and Weikusat, I.: Location and distribution of micro-inclusions in the EDML and NEEM ice cores using optical microscopy and in situ Raman spectroscopy, The Cryosphere, 11, 1075-1090, doi:10.5194/tc-11-1075-2017, 2017.

Fuhrer, K., Wolff, E. W., and Johnsen, S. J.: Timescales for dust variability in the Greenland Ice Core Project (GRIP) ice core in the last 100,000 years, J. Geophys. Res.-Atmos., 104, 3104331052, 1999.

Gillette, D. A. and Passi, R.: Modeling dust emission caused by wind erosion, J. Geophys. Res.-Atmos., 93, 14233-14242, 1988.

Huang, J. and Jaeglé, L.: Wintertime enhancements of sea salt aerosol in polar regions consistent with a sea ice source from blowing snow, Atmos. Chem. Phys., 17, 3699-3712, doi:10.5194/acp-17-3699-2017, 2017.

Jochum, K. P., Weis, U., Stoll, B., Kuzmin, D., Yang, Q., Raczek, I., Jacob, D. E., Stracke, A., Birbaum, K., Frick, D. A., Günther, D., and Enzweiler, J.: Determination of reference values for NIST SRM 610-617 glasses following ISO guidelines, Geostandard. Geoanal. Res., 35, 397-429, 2011.
Kreutz, K. J. and Koffman, B.: Glaciochemistry, in: Encyclopedia of Quaternary Science 2nd edition, edited by: Elias, S., Elsevier Publishers, 326-333, 2013.

Kutzbach, J. E., Guetter, P. J., Behling, P. J., and Selin, R.: Simulated climatic changes: results of the COHMAP climate-model experiments. Global climates since the last glacial maximum, University of Minnesota Press, Minneapolis, 5-11, 24-93, 1993.

Lewis, E. R. and Schwartz, S. E.: Sea salt aerosol production: mechanisms, methods, measurements, and models-A critical review, Geophysical Monograph, vol. 152. American Geophysical Union, Washington, DC, 413 pp., 2004.

Mahowald, N., Kohfeld, K., Hansson, M., Balkanski, Y., Harrison, S. P., Prentice, I. C., Schulz, M., and Rodhe, H.: Dust sources and deposition during the last glacial maximum and current climate: A comparison of model results with paleodata from ice cores and marine sediments, J. Geophys. Res.-Atmos., 104, 15895-15916, 1999.

Müller, W., Shelley, M., Miller, P., and Broude, S.: Initial performance metrics of a new custom-designed ArF excimer LAICPMS system coupled to a two-volume laser-ablation cell, J. Anal. Atom. Spectrom., 24, 209-214, 2009.

Müller, W., Shelley, J. M. G., and Rasmussen, S. O.: Direct chemical analysis of frozen ice cores by UV-laser ablation ICPMS, J. Anal. Atom. Spectrom., 26, 2391-2395, 2011.

Petit, J. R., Jouzel, J., Raynaud, D., Barkov, N. I., Barnola, J. M., Basile, I., Bender, M., Chappellaz, J., Davis, M., Delaygue, G., Delmotte, M., Kotlyakov, V. M., Legrand, M., Lipenkov, V. Y., Lorius, C., Pépin, L., Ritz, C., Saltzman, E., and Stievenard, M.: Climate and atmospheric history of the past 420,000 years from the Vostok ice core, Antarctica, Nature, 399, 429-436, 1999.

Rasmussen, S. O., Bigler, M., Blockley, S. P., Blunier, T., Buchardt, S. L., Clausen, H. B., and Winstrup, M.: A stratigraphic framework for abrupt climatic changes during the Last Glacial period based on three synchronized Greenland ice-core records: refining and extending the INTIMATE event stratigraphy, Quaternary Sci. Rev., 106, 14-28, 2014.

Reinhardt, H., Kriews, M., Miller, H., Lüdke, C., Hoffmann, E., and Skole, J.: Application of LA-ICP-MS in polar ice core studies, Anal. Bioanal. Chem., 375, 1265-1275, 2003.

Ruth, U., Wagenbach, D., Steffensen, J. P., and Bigler, M.: Continuous record of microparticle concentration and size distribution in the central Greenland NGRIP ice core during the last glacial period, J. Geophys. Res., 108, 4098, doi:10.1029/2002JD002376, 2003.

Sneed, S. B., Mayewki, P. A., Sayre, W., Handley, M. J., Kurbatov, A. V., Taylor, K. C., Bohleber, P., Wagenbach, D., Erhardt, T., and Spaulding, N. E.: Instruments and Methods New LA-ICPMS cryocell and calibration technique for sub-millimeter analysis of ice cores, J. Glaciol., 61, 233-242, 2015.

Steffensen, J. P., Andersen, K. K., Bigler, M., Clausen, H. B., DahlJensen, D., Fischer, H., Goto-Azuma, K., Hansson, M., Johnsen, S. J., Jouzel, J., Masson-Delmotte, V., Popp, T., Rasmussen, S. O. R., Röthlisberger, R., Ruth, U., Stauffer, B., Siggaard-Andersen, M. L., Sveinbjörnsdóttir, Á. E., Svensson, A., and White, J. W. C.: High-resolution Greenland ice core data show abrupt climate change happens in few years, Science, 321, 680-684, 2008.

Thomas, E. R., Wolff, E. W., Mulvaney, R., Johnsen, S. J., Steffensen, J. P., and Arrowsmith, C.: Anatomy of a DansgaardOeschger warming transition: High-resolution analysis of the 
north Greenland ice core project ice core, J. Geophys. Res.Atmos., 114, D08102, 2009.

Vallelonga, P., Bertagna, G., Blunier, T., Kjær, H. A., Popp, T. J., Rasmussen, S. O., Steffensen, J. P., Stowasser, C., Svensson, A. S., Warming, E., Winstrup, M., Bigler, M., and Kipfstuhl, S.: Duration of Greenland Stadial 22 and ice-gas $\Delta$ age from counting of annual layers in Greenland NGRIP ice core, Clim. Past, 8, 1839-1847, doi:10.5194/cp-8-1839-2012, 2012.

Wilhelm-Dick, D.: Enhanced analysis of stratified climate archives through upgrade of Laser Ablation Inductively Coupled Plasma Quadrupole to Time of Flight Mass Spectrometry?, Doctoral dissertation, Berlin, Univ., Diss., 2008.
Wolff, E. W., Chappellaz, J., Blunier, T., Rasmussen, S. O., and Svensson, A.: Millennial-scale variability during the last glacial: The ice core record, Quaternary Sci. Rev., 29, 2828-2838, 2010.

Yung, Y. L., Lee, T., Wang, C. H., and Shieh, Y. T.: Dust: A diagnostic of the hydrologic cycle during the Last Glacial Maximum, Science, 271, 962-963, 1996.

Zhang, X. Y., Arimoto, R., and An, Z. S.: Dust emission from Chinese desert sources linked to variations in atmospheric circulation, J. Geophys. Res.-Atmos., 102, 28-41, 1997. 